\title{
Experimental and Numerical Modal Analysis of the Carbon Composite Plate Damaged by Cut
}

Ján Vavro jr., Ján Vavro, Alena Vavrová

Faculty of Industrial Technologies in Púchov, Alexander Dubček University of Trenčín. I. Krásku 491/30, 02001 Púchov.

Slovac Republic. E-mail: jan.vavro.jr@fpt.tnuni.sk, jan.vavro@fpt.tnuni.sk, alena.vavrova@azet.sk

The given paper is closely connected with the experimental and numerical modal analysis of the carbon composite plate damaged by cut. In relation to the tested carbon composite, modal analysis was performed by help of special measuring device Pulse 12. The mentioned device was supplied by company Brüel \& Kjear and the experimental measurements were carried out using damaged and undamaged plate sample which were prepared from the mentioned material hereinbefore. The investigated and analyzed plates of carbon composite were made of six layers of carbon fibres and they were arranged under the angle $90^{\circ}$ (it is like fabric material made off carbon fibres). The layers arranged in the given way were joined by epoxide resin MGS 285. The experimental measurement of eigenfrequencies of carbon composite plates was carried out using the undamaged and damaged sample with proportions $78 \mathrm{~mm} \times 78 \mathrm{~mm}$ while ten measurements were performed for each one specified site of the sample. In relation to the damaged plate sample, there was cut in length of $20 \mathrm{~mm}$ in the centre border. The finite element method in the software system ADINA v.8.6.2 was used for numerical analysis of the eigenf requencies.

Keywords: modal analysis, eigenfrequencies, carbon composite, finite element method

\section{Introduction}

The experimental modal analysis belongs to Dynamics that is the special scientific field where so-called modal parameters of the object (e.g. eigenfrequencies, own shapes of the vibrations, absorption or damping parameters) are investigated. These mentioned parameters can be obtained in an analytical way by help of finite element analysis (FEM) or they can be determined on the basis of the experimental analysis. The experimental analysis is connected with verification or completing of those results which were acquired on the basis of the analytical method. The given analysis is based on the principle which involves the usage of the process where the complex vibration process is divided into the simple modal constituent vibrations or parts. Each one of these constituent parts can be characterized by its natural frequency or eigenfrequency as well as it has its own shape of the vibration $[1,2]$. The sixties of last century can be understood as the beginning of the modern era of the experimental modal analysis (EMA) because of the introduction of Fourier transformation and development and progress relating to the computer technologies. Nowadays, experimental modal analysis (EMA) represents the scientific field which stands for some connecting point between signal adjustment and computational technology, theory of mechanics, vibrations, acoustics and signals processing $[3,6]$.

EMA can be also used for verification of the mathematical models and nowadays, it can help us to solve various technical problems including $[4,5,7,8]$ :

- the determination of eigenfrequencies for any objects because if the excitation frequencies correspond to eigen frequencies, it can lead to excessive vibrations of the construction (resonance) and it means the decrease of lifetime and reliability,
- the determination of the own or natural shapes of the vibration and control them by exciting actions of the system with the aim to find the critical site of the construction where the vibration is the highest,

- the verification of the authenticity relating to the mathematical models which were made by help of finite element methods and moreover, the change of models parameters can be done by help of experiments and measurements in order to obtain the mutual accordance (modal tuning),

- the modification and the change of construction geometry with the aim to eliminate the intervals or zones of in-service exciting actions (structural modification).

\section{Acceleration piezoelectric sensor $4524-b$}

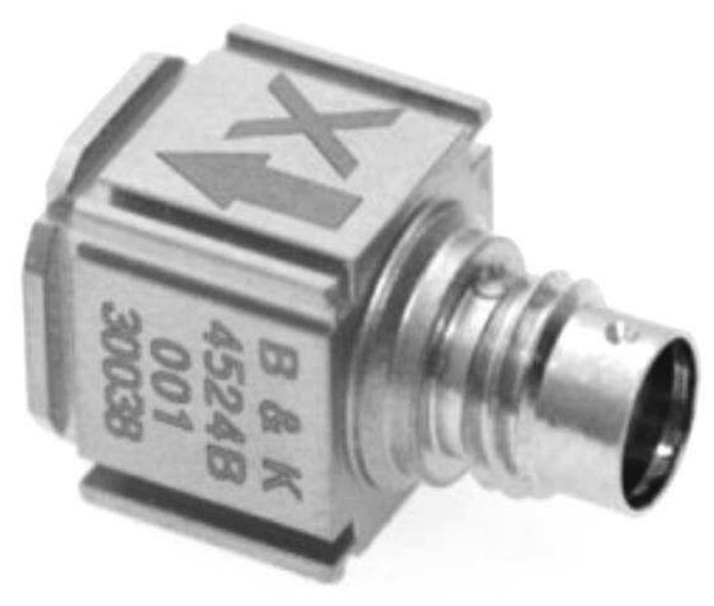

Fig. 1 Accelerometer of type 4524-B 
The piezoelectric sensor 4524-B (see Fig.1) is the lightweight and three-axial sensor with three independent out-puts for the simultaneous measurement in three directions and these directions are perpendicular to each other. The brief description of the given sensor is given in the Tab. 1 and it is the specification provided by manufacturer.

Tab. 1 The brief description of the accelerometer

\begin{tabular}{|l|l|l|l|}
\hline \multirow{2}{*}{$\begin{array}{l}\text { Technical } \\
\text { parameter }\end{array}$} & \multicolumn{3}{|c|}{ Accelerometer 4524-B } \\
\cline { 2 - 4 } & $\mathrm{x}$ & $\mathrm{y}$ & $\mathrm{z}$ \\
\hline $\begin{array}{l}\text { Sensitivity } \\
{\left[\mathrm{mV} / \mathrm{ms}^{-2}\right]}\end{array}$ & 9.963 & 9.882 & 9.924 \\
\hline $\begin{array}{l}\text { Frequency } \\
\text { range [Hz] }\end{array}$ & $\begin{array}{l}0.2- \\
5.5 \mathrm{k}\end{array}$ & $\begin{array}{l}0.25- \\
3.0 \mathrm{k}\end{array}$ & $\begin{array}{l}0.25- \\
3.0 \mathrm{k}\end{array}$ \\
\hline $\begin{array}{l}\text { Installed reso- } \\
\text { nance frequency } \\
{[\mathrm{kHz}]}\end{array}$ & 18 & 9 & 9 \\
\hline Weight [g] & 4.4 & \multicolumn{3}{|l}{} \\
\hline
\end{tabular}

\section{The operating environment of the eigen- frequencies}

It has already been mentioned that the software PULSE enables us to carry out settings, actuation and documentation of the measurement by help of organizers and according to this mentioned fact, the accurate pattern can be made to be used for the specific project. In our case, the pattern MTC Hammer was used for measurement of the modal analysis. The first step of the given pattern is connected with the settings of the fixed accelerometer and moving point relating to the hammer impact. Modal hammer and tree-axial sensor were set on the individual channels in the configuration organizer. In relation to geometry configuration, the sample was created as well as the position of the measuring accelerometer and hammer was determined and it led to the creation of the measurement plan (see Fig. 2). The next one step involved the setting of the force of hammer impact and this set force was used during the whole process of the measurement. The individual windows were also determined and after the activation of the pattern, the measurement process was carried out. The Fig. 2 shows the position of the accelerometer which was in the centre of the sample and hammer impacts were carried out on four specified sites - in the individual corners of the samples.

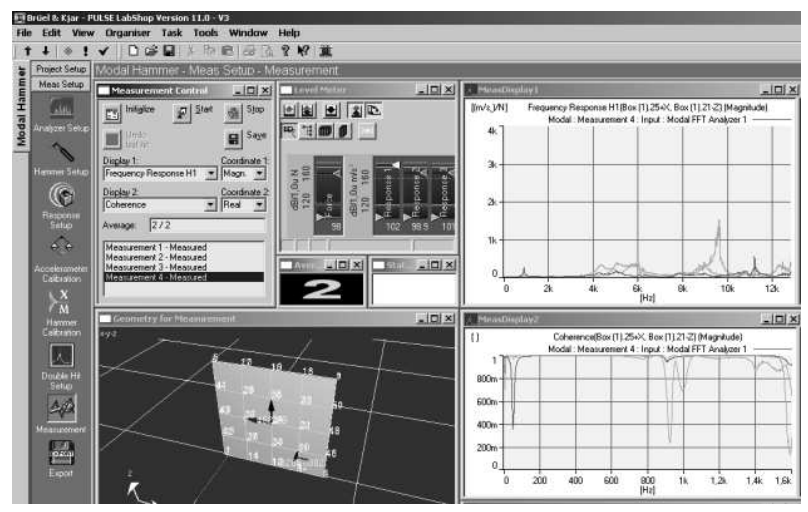

Fig . 2 Measurement by the system PULSE
For each one site, the frequencies obtained on the basis of ten hammer impacts were recorded and they were subsequently averaged, evaluated and displayed in the graphical way by Pulse system in graphs of the frequency response and coherency. The software which is supplied together with the measurement device is used for settings, controlling, and collection of obtained measurement data. The given software contains everything which is needed for measurement. The measurement process as well as setting of the required conditions is done by help of organizers and the user can make settings of software according to own requirements. The given settings can be saved and used as some pattern again during any other measurement.

\section{Experimental measurement of the eigen- frequencies}

The experimental measurements were performed by help of special device PULSE 12 from company Brüel \& Kjear. The samples obtained from carbon composite material were used for measurement process. The mentioned composites were made of six layers of carbon fibres and they were arranged under the angle $90^{\circ}$ (it is like fabric material composed of carbon fibres). Then, the layers arranged in the given way were joined by epoxide resin MGS 285.

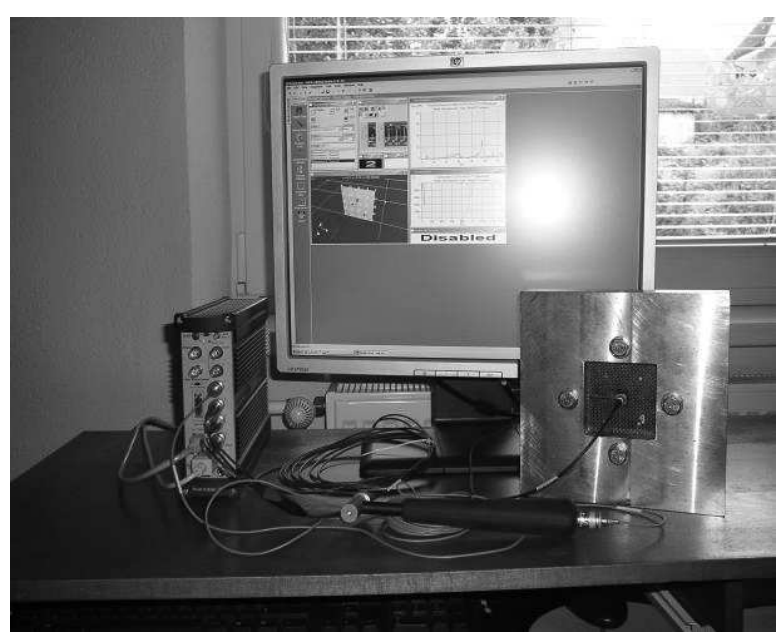

Fig. 3 Model of rotating blade wheel

The experimental measurement of eigenfrequencies for carbon composite was carried out using the undamaged and damaged samples with proportions $78 \mathrm{~mm} x$ $78 \mathrm{~mm}$. In relation to the damaged plate sample, there was cut in length of $20 \mathrm{~mm}$ in the centre border. The samples were held around the whole circumference in special fixture and moreover, they were between two plates which were fastened by four screws. The testing equipment for experimental measurement can be seen in Fig 3. For each one site, the frequencies obtained on the basis of ten hammer impacts were recorded and they were subsequently averaged, evaluated and displayed in the graphical way by Pulse system in graphs of the frequency response and coherency. The software which is supplied together with the measurement device is used for settings, controlling, and collection of obtained measurement data. The given 
software contains everything which is needed for measurement. The measurement process as well as setting of the required conditions is done by help of organizers and the user can make settings of software according to own requirements. The given settings can be saved and used as some pattern again during any other measurement. As can be seen in Fig. 3, the position of the accelerometer for the undamaged sample was in the centre and hammer impacts were performed for four sites - in the corners of the sample. The obtained eigenfrequencies for both types of samples are shown in Tab.2.

Tab. 2 Obtained values of eigenfrequencies for damaged and undamaged sample of the carbon composite

\begin{tabular}{|l|l|l|}
\hline \multicolumn{3}{|c|}{ Obtained values of eigenfrequencies $(\mathrm{Hz})$} \\
\hline $\begin{array}{l}\text { Number of } \\
\text { frequency }\end{array}$ & $\begin{array}{l}\text { Undamaged } \\
\text { sample }\end{array}$ & $\begin{array}{l}\text { Damaged } \\
\text { sample }\end{array}$ \\
\hline 1 & 5030.89 & 4796.23 \\
\hline 2 & 6160.26 & 5936.86 \\
\hline 3 & 8550.60 & 7915.60 \\
\hline 4 & 9902.33 & 9057.48 \\
\hline 5 & 10942.10 & 10532.00 \\
\hline
\end{tabular}

\section{Numerical analysis of the eigenfrequencies}

The specific method, called "Subspace iteration" method was used for creation of the computational model in the program system ADINA 2.8.6. The material constant parametres were used for epoxide matrix L 285 as well as for carbon fibres and these constant parametres, shown in Tab. 3, were specified by the producer.

Tab. 3 Material constant parameters which were used for computational model

\begin{tabular}{|c|c|c|}
\hline $\begin{array}{c}\text { Material constant } \\
\text { parameter }\end{array}$ & $\begin{array}{c}\text { Epoxide ma- } \\
\text { trix L 285 }\end{array}$ & $\begin{array}{c}\text { Carbon } \\
\text { fibre }\end{array}$ \\
\hline $\mathrm{E}[\mathrm{GPa}]$ & 3.45 & 380 \\
\hline$\mu$ & 0.3 & 0.33 \\
\hline$\rho\left[\mathrm{kg} / \mathrm{m}^{3}\right]$ & 1200 & 1950 \\
\hline
\end{tabular}

Numerical analysis was solved for two computational models:

- $\quad$ for undamaged sample with the proportions 78 $\mathrm{mm} \times 78 \mathrm{~mm}$ and it was reinforced with six layers of carbon fibres while the fibres were arranged under angle $90^{\circ}$;

- for damaged sample,there was a cut in the centre border of the sample and the length was $20 \mathrm{~mm}$.

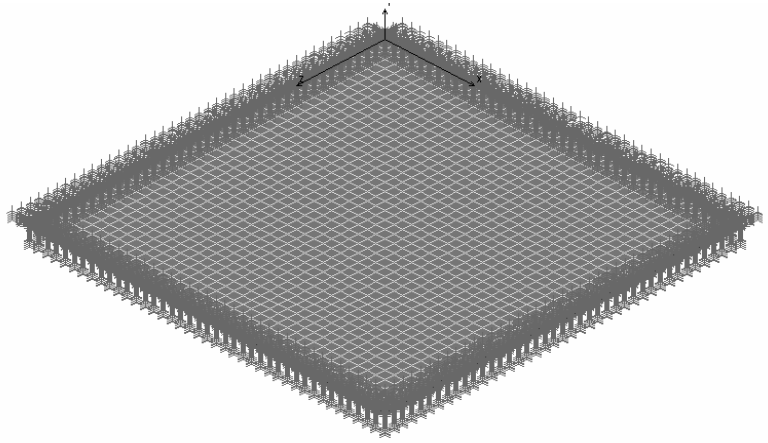

Fig.4 Computational model of the undamaged carbon fibre sample
The computational model of the undamaged composite as well as its first five shapes of eigenfrequencies can be seen in the Fig. 4 to Fig. 9 .

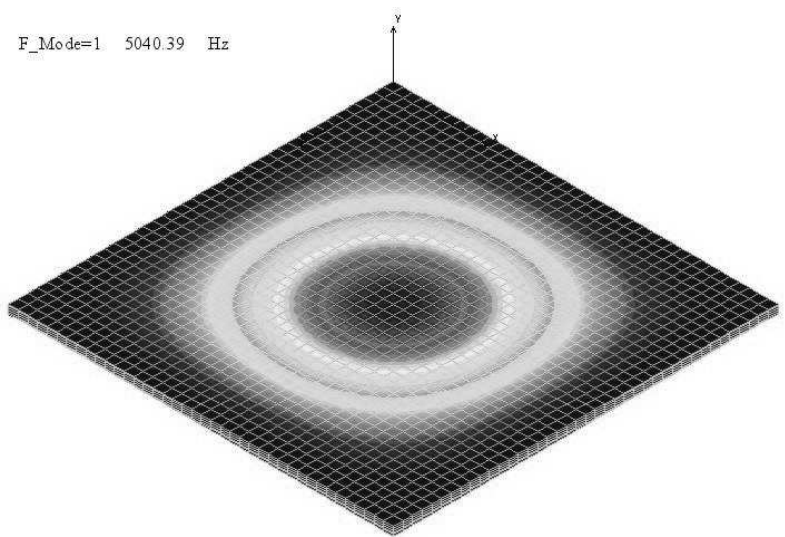

Fig.5 The first shape of the eigenfrequency

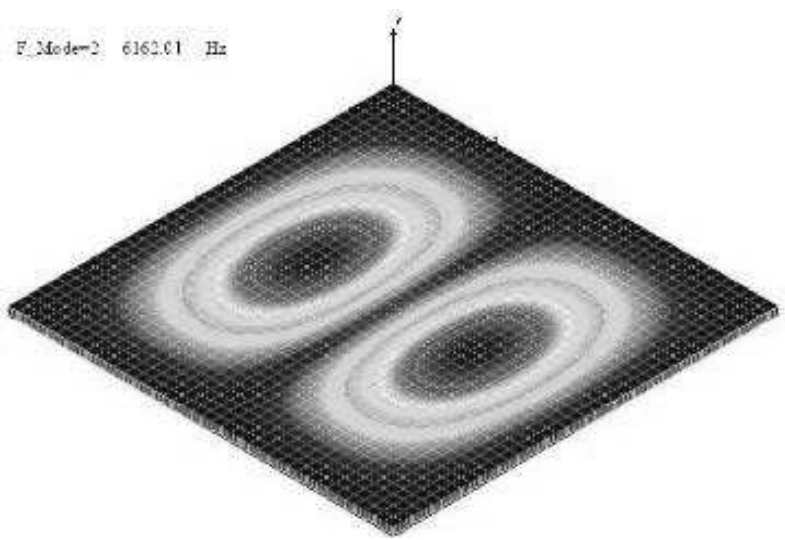

Fig.6 The second shape of the eigenfrequency

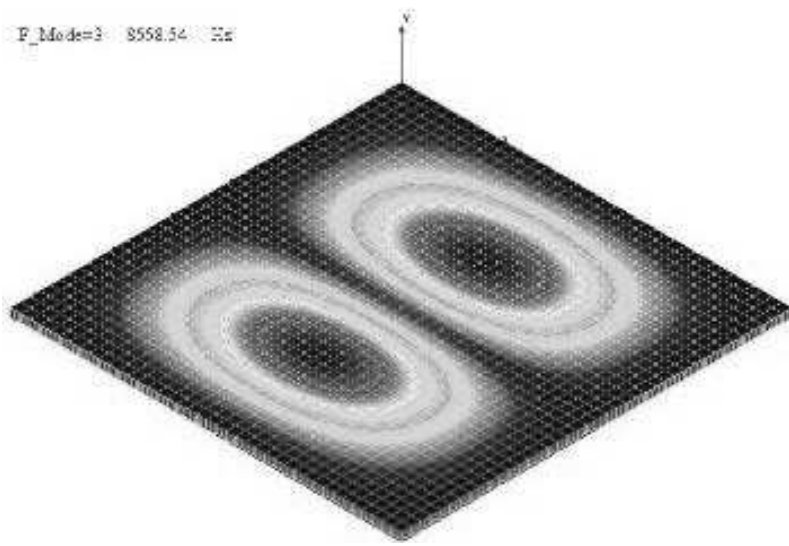

Fig.7 The third shape of the eigenfrequency

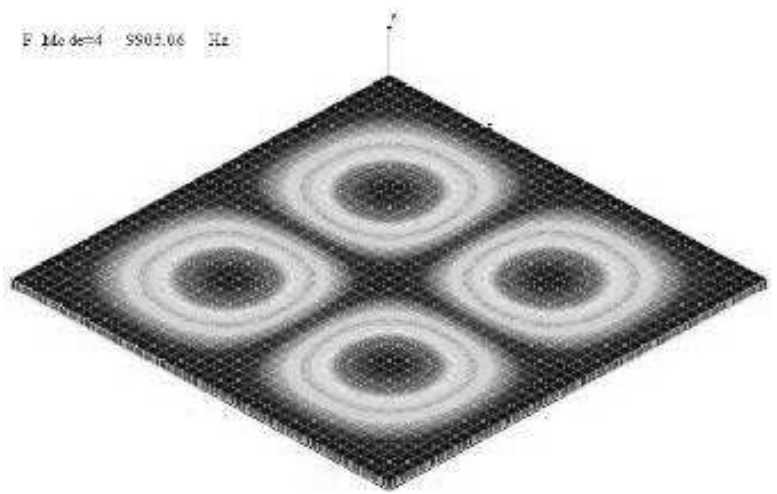

Fig.8 The fourth shape of the eigenfrequency 


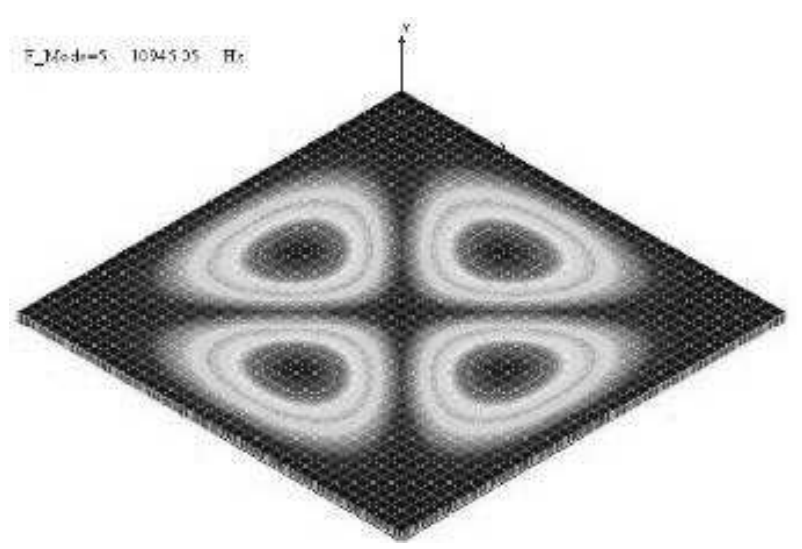

Fig.9 The fifth shape of the eigenfrequency

The computational model of the damaged composite sample with the cut in the centre of border of the sample with the length of $20 \mathrm{~mm}$ as well as its first five shapes of eigenfrequencies can be seen in the Figs. 10 - 15. The given own or natural shapes represent the dynamic behaviour of the model or possible movement of the system vibrations and they are ordered from the lowest frequency to the highest one. In relation to the individual models, the own or natural shapes of the eigenfrequencies depend on the way of removal of the degrees of freedom and they also depend on size and shape of the defect as well as the location or site of the defect on the model. The first one shape represents the lowest frequency and the fifth shape represents the highest frequency. The calculated results of eigenfrequencies for the damaged and undamaged samples are introduced in Tab. 4.

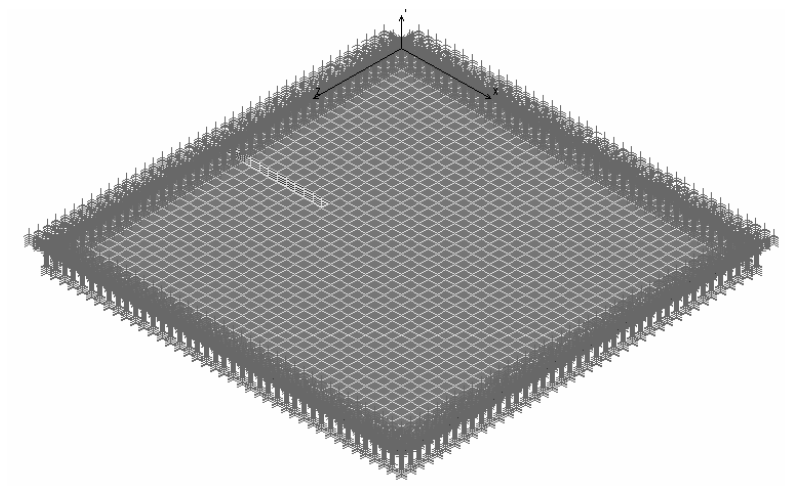

Fig.10 Computational model of the damaged carbon fibre sample

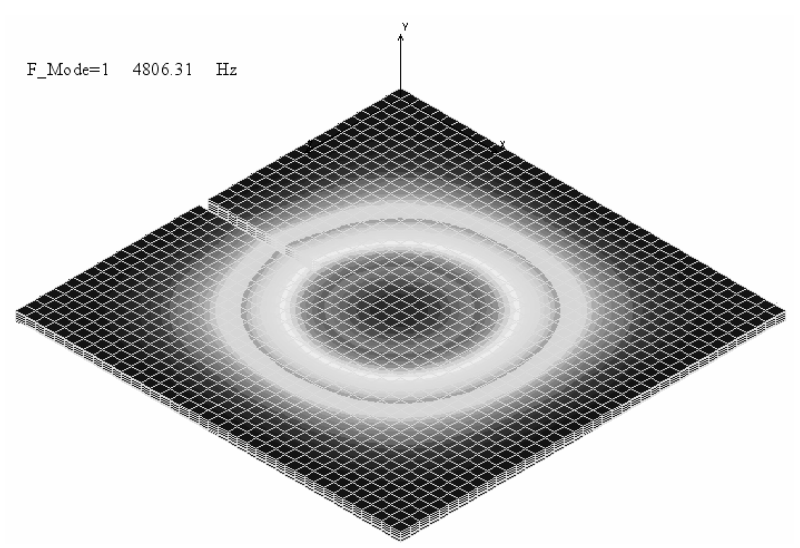

Fig.11 The first shape of the eigenfrequency

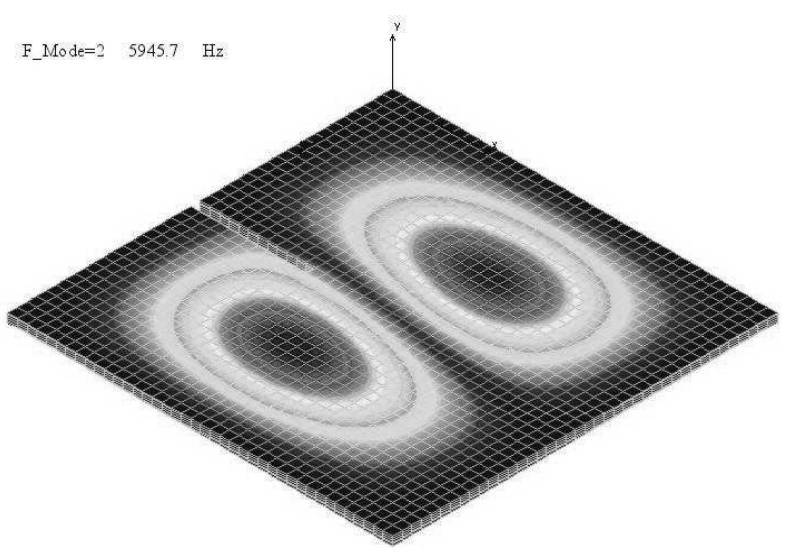

Fig.12 The second shape of the eigenfrequency

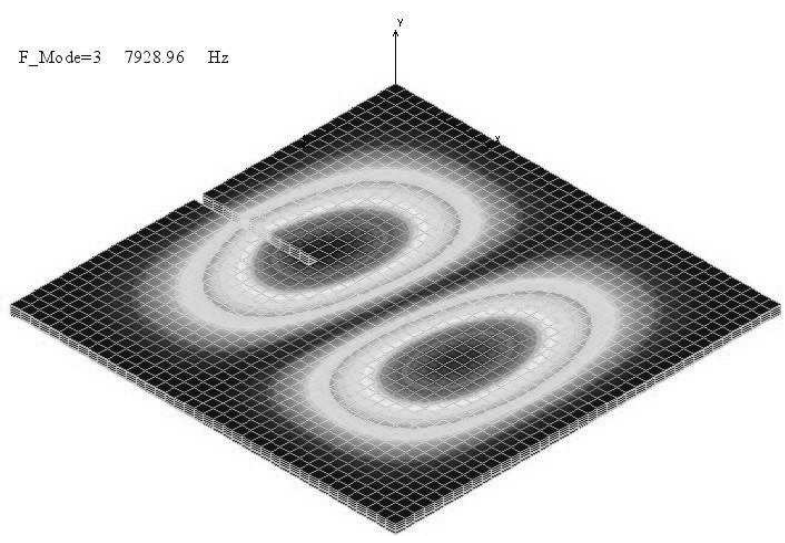

Fig.13 The third shape of the eigenfrequency

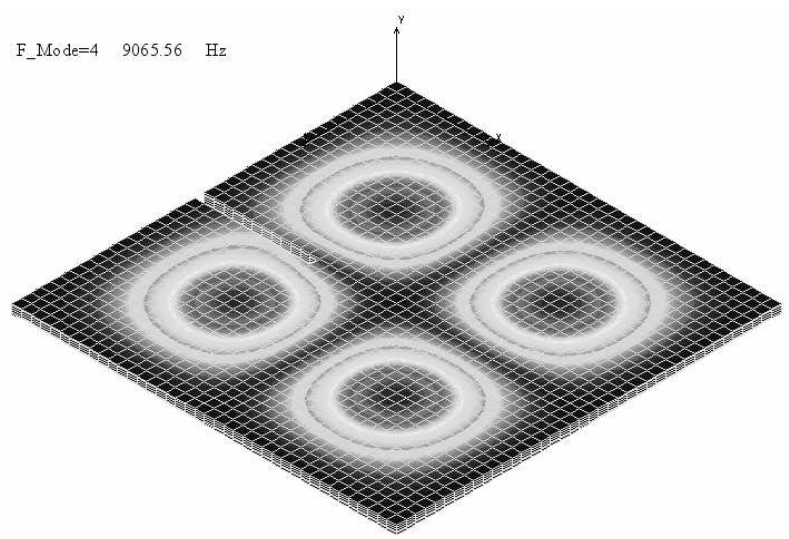

Fig.14 The fourth shape of the eigenfrequency

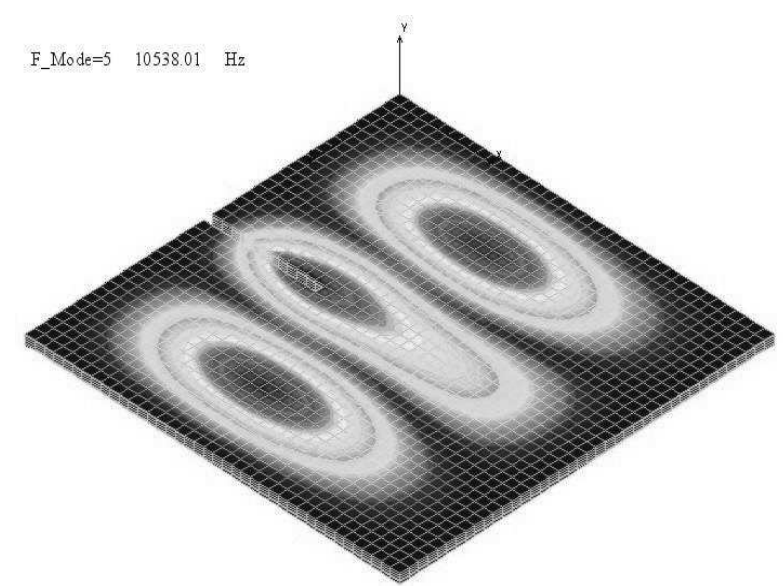

Fig.15 The fifth shape of the eigenfrequency 
Tab. 4 Calculation of the eigenfrequencies for damaged and undamaged sample

\begin{tabular}{|l|l|l|}
\hline \multicolumn{3}{|c|}{ Calculation values of eigenfrequencies (Hz) } \\
\hline $\begin{array}{l}\text { Number of } \\
\text { frequency }\end{array}$ & $\begin{array}{l}\text { Undamaged } \\
\text { sample }\end{array}$ & $\begin{array}{l}\text { Damaged } \\
\text { sample }\end{array}$ \\
\hline 1 & 5040.39 & 4806.31 \\
\hline 2 & 6162.01 & 5945.7 \\
\hline 3 & 8558.54 & 7928.96 \\
\hline 4 & 9905.06 & 9065.56 \\
\hline 5 & 10945.05 & 10538.01 \\
\hline
\end{tabular}

\section{Conclusion}

As mentioned above, ten measurements were performed for the each one tested site of the sample. Tab. 2 shows the average value resulting from all ten measurements which were performed for four specified sites of the sample. According to the obtained results based on measurement, it can be concluded that the frequencies of the damaged sample are less than the frequencies of the undamaged sample. The same results were obtained in the case of the numerical analysis which was based on the finite element method and it is shown in Tab. 4. The measurement range of the frequencies was given up to 14 $000 \mathrm{~Hz}$. According to results which were obtained on the basis of measurement of frequencies (Tab. 2) and results which were obtained on the basis of the calculation of the frequencies (Tab. 4), it can be assessed that increase of the frequency leads to the higher value of the shift in relation to the comparison of the damaged and undamaged sample - the difference of the frequencies is noticeable.

\section{Acknowledgement}

This work was supported by the Slovak Grant Agency VEGA 1/0649/17, KEGA 007TnUAD-4/2017, and resulted from the project "Center for quality testing and diagnostics of materials", ITMS code 26210120046 relating to the Operational Program Research and Development funded from European Fund of Regional Development.

\section{References}

[1] ALLEMANG, R.J., (1994). Analytical and Experimental Modal Analysis, UC-SDRLCN.

[2] AVITABILE, P., (2001). Experimental modal Analysis. A simple non-mathematical presentation. University of Massachusetts.

[3] DIZO, J., BLATNICKÝ, M. (2019). Evaluation of Vibrotional Properties of a Three-wheeled Vehicle in Terms of Comfort, Manufacturing Technology, Volume 19, ISSN 1213-2489, pp. 197-203.

[4] KLIMENDA, F., SOUKUP, J., ZMINDAK, M. (2016). Deformation of Aluminium Thin Plate, Manufacturing Technology, Volume 16, , ISSN 1213-2489, pp. 124-129.

[5] KULHAVÝ, P., FLIEGEL, V. (2019). Experimental and Numerical Analysis of Dynamic Properties of Wound and Wrapped Carbon Composites, Manufacturing Technology, Vol.18, ISSN 1213-2489, pp.248-253.

[6] SVOBODA, M., SOUKUP, J. (2013). Verification of Numeric Solution by Experiment for Examination Vetical Oscilation of Mechanical System, Manufacturing Technology, No. 4, ISSN 1213-2489, pp. 559-563.

STANKOVIČOVÁ, Z., DEKÝŠ, V., NOVÁK, P., SAPIETA, M (2015). Numerical Simulation of Thermoelastic Stress Analysis, Manufacturing Technology, Volume 15, , ISSN 1213-2489, pp. 925-930.

[7] YONGYI LIAO, BAIYU LIAO, (2019). Dynamics Modeling and Modal Analysis of Machine ool Considering Joints Parameters, Manufacturing Technology, Volume 19, ISSN 1213-2489, pp. 267-272. 